\title{
Göksu Irmağı (Türkiye) Güncel Balık Faunası ve Ekolojik Durumunun Değerlendirilmesi
}

\author{
Fahrettin KÜÇÜK ${ }^{1 *}$ İskender GÜLLE ${ }^{2} \quad$ Salim Serkan GÜÇLÜ ${ }^{1} \quad$ Davut TURAN $^{3}$ \\ ${ }^{1}$ Isparta Uygulamalı Bilimler Üniversitesi, Eğirdir Su Ürünleri Fakültesi, Isparta, Türkiye \\ ${ }^{2}$ Burdur Mehmet Akif Ersoy Üniversitesi Fen-Edebiyat Fakültesi Biyoloji Bölümü, Burdur, Türkiye \\ ${ }^{3}$ Recep Tayyip Erdogan Üniversitesi Su Ürünleri Fakültesi, Rize, Türkiye
}

Atıf yapmak için: Küçük, F., Gülle, I., Güçlü, S.S. \& Turan, D. (2021). Göksu Irmağı (Türkiye) Güncel Balık Faunası ve Ekolojik Durumunun Değerlendirilmesi. Anadolu Çev. ve Hay. Dergisi, 6(4), 705-711.

How to cite: Küçük, F., Gülle, I., Güçlü, S.S. \& Turan, D. (2021). Current Fish Fauna of Göksu River (Turkey) and Evaluation of Its Ecological Status. J. Anatolian Env. and Anim. Sciences, 6(4), 705-711.

*Sorumlu yazarın:

Fahrettin KÜCÜK

Isparta Uygulamalı Bilimler Üniversites

Eğirdir Su Ürünleri Fakültesi, Isparta,

Türkiye

凶: fahrettinkucuk@isparta.edu.tr
Öz: Orta Toroslar'daki karst alanlardan beslenen Göksu Irmağı, Doğu Akdeniz Havzası'nın Akdeniz'e dökülen en büyük akarsuyudur. Bu çalışmada, 2014-2017 yılları arasında farklı tarihlerde yapılan örnekleme, gözlem ve literatür taraması 1şığında; Göksu Irmağı balık faunasının güncel taksonomik durumu, dağılım alanları, IUCN koruma ölçütleri ve akarsu bölgelerinin ekolojik yapısı değerlendirilmiştir. Çalışmamızda akarsuyun acısu bölgesi hariç 8 familyadan; 7'si yerli, 2'si egzotik ve 2'si göç eden tür (diadrom) olmak üzere toplam 11 tür belirlenmiş olup, bunlardan 6's1 Türkiye için endemiktir. Akarsuyun üst havzasındaki bu yüksek endemizm oranı oldukça dikkat çekicidir. Irmağın ana kollarını oluşturan, yukarı-orta havza drenaj alanı içerisindeki Göksu Çayı ve Ermenek Çayı (Gevne Çayı)'nın üzerinde gerçekleşen karayolu, köprü, baraj ve HES yapımı gibi fiziki tahribatların akarsu ekosisteminin doğal yapısını bozduğu, akarsu yatağında kısmi kurumalar ve habitat parçalanmasına neden olduğu gözlemlenmiştir. Bu baskılar sonucunda, Göksu Çayı ve Gevne Çayı'nın baskın balık türü olan endemik Toros sirazı (Capoeta caelestis) popülasyon yoğunluğunun önemli ölçüde azaldığı tespit edilmiştir. Aynı olumsuz etkenler nedeniyle Gevne Çayı'nın Beyreli Köyü (Hadim-Konya) ile Dumlugöze (Sarıveliler-Karaman) arasında kalan yaklașık 45 km'lik üst kesiminde 2004-2009 yılları arasında nadiren örneklenen kırmızıbenekli alabalık (Salmo opimus) popülasyonunun yok olduğu belirlenmiştir.

Anahtar kelimeler: Akarsu ekolojisi, balık faunası, cevresel etki, koruma ölçütleri.

\section{Current Fish Fauna of Göksu River (Turkey) and Evaluation of Its Ecological Status}

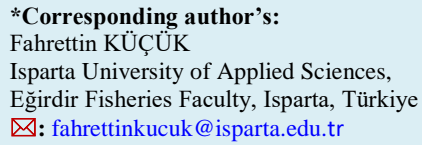

\begin{abstract}
The Göksu River, fed by the Central Taurus karst areas, is the largest river of the Eastern Mediterranean Basin flowing into the Mediterranean. In this study, within the scope of the samples and observations we made on different dates between 2014-2017, and in the light of other research findings; the current taxonomic status of the Göksu River fish fauna, distribution areas, IUCN conservation criteria and ecological structure of the river regions were evaluated. In our study, except for the brackish water region of the stream; A total of 11 taxa were identified, belong to 8 families; 7 native (as 6 endemic and 1 widespread), 2 exotic and 2 migratory (diadromous). The high rate of endemism in the upper basins of the river is quite remarkable. There have been physical destructions such as the construction of highways, bridges, dams and HEPPs on Göksu Stream and Ermenek Stream (Gevne Stream) within the upper-middle basin drainage area, which form the main branches of this river. It has been observed that these destructions disrupt the natural structure of the river ecosystem, causing partial drying in the river bed and habitat fragmentation. As a result of these pressures on the stream, it has been determined that the population density of the endemic Taurus scraper (Capoeta caelestis), which is the dominant fish species of Göksu and Gevne streams, has decreased significantly. Due to the same negative factors, it was determined that the red spotted trout (Salmo opimus) population, which was rarely sampled between 2004 and 2009, disappeared in the upper part of the Gevne Stream, approximately $45 \mathrm{~km}$ between Beyreli Village (Hadim-Konya) and Dumlugöze (Sarıveliler-Karaman).
\end{abstract}




\section{GíRiş}

Göksu Irmağı, Doğu Akdeniz Havzası'nın en büyük akarsuyudur. Orta Toroslar'ın $1500 \mathrm{~m}$ yükseltisindeki dağlık alanlardan doğan ırmağın yukarı havzasında neojen tortul ve karstik karbonat ana kayası hakimdir. Dik bir topografyaya sahip olan Göksu havzası, neojen tortul ve karbonat ana kayalarına oyulmuş derin vadiler ve geçitler ile karakterize olmuştur (Akbulut vd., 2009). Doğu Akdeniz Havzası'nın 11.213 km² ile en büyük drenaj alanına sahip bu akarsu $260 \mathrm{~km}$ uzunluğunda olup; Antalya, Konya, Karaman ve Mersin il sınırları içerisinde yer almaktadır (Tekin \& Can, 2019). Mut İlçesi’nin yukarısında kalan kolları üst havzayı olușturmakta iken, buradan Akdeniz'e kadar olan yaklaşık 126 km uzunluğundaki kısım aşağı havzayı temsil etmektedir (Yildırım vd., 2018).

Göksu Çayı (veya Hadim Göksuyu) Mut İlçesi yakınlarındaki "Suçatı" bölgesinde diğer büyük kol olan Ermenek Çayı (veya Ermenek Göksuyu) ile birleșerek "Göksu Irmağı" adını alır. Aşağı havzada Pirinç Suyu, Murat Çayı ve Kurtsuyu Çayı da ırmağa karışarak, Silifke'nin güneyinden kendi adını taşıyan deltadan Akdeniz'e dökülür (Munsuz \& Ünver, 1983; Küçük vd., 2007).

Akarsuyun balık faunasına ilişkin ilk kayıtlar Ladiges (1966), Balık (1980) ve Bogutskaya (1997) tarafından yapılmış, yakın dönemde yapılan en kapsamlı çalışmada ise 7 familyaya ait 13 takson kaydı verilmiştir (Küçük vd., 2007). Bunların dışında Doğa Koruma ve Milli Parklar Genel Müdürlüğü’nce yaptırılan “Karaman İli Biyolojik Çeşitlilik Envanter ve İzleme Projesi (2016)" kapsamında; Göksu Irmağı'nın yukarı havzasındaki balıkların güncel sistematik durumu ve yayılış alanlarına ilişkin ayrıntılı bir proje raporu bulunmaktadır (Küçük vd., 2017a). Bunun yanı sıra, ırmağın akarsu ağzı ile ilk 6 km arasında kalan acısu (östarin) bölgesinde yaşayan deniz ve tatlısu kökenli türlerin listesi İnnal vd., (2020) tarafindan ayrıntılı bir şekilde çalışılmıştır. Bu bilimsel kayıtlara ek olarak, yakın zamanda ırmağın yukarı havzasından yeni bir nemachilid türü tanımlanmıştır (Çiçek vd., 2020; Yoğurtçuoğlu vd., 2020). Yukarıda sözü edilen çalışmalar 1şı̆̆ında, havzanın genelini kapsayan en son araştırmanın yapıldığg 2007 'den bu yana, yeni balık türleri kaydedilmiş olmasına karşın; son yıllarda havzanın neredeyse tamamını kapsayan karayolu, köprü, baraj ve HES yapımı gibi fiziki değişimlerin akarsu hidrolojisine, dolayısıyla balık faunası ve habitatlar üzerine yaptığı olumsuzlukların havzanın genelini kapsayacak şekilde yeniden gözden geçirilmesi gerekliliği doğmuştur. Bu amaçla, çalışmamızda ırmağın acısu (östarin) bölgesi dışında kalan kısımlarının balık faunası çeşitliliği, güncel taksonomik durumu ve habitatlarının ekolojik yapısı araştırılmıştır.

\section{MATERYAL VE METOT}

Göksu Irmağı havzasının deniz seviyesinden ortalama yüksekliği 1276 m, yıllık ortalama su akımı 95,2 m3/s'dir (Akbulut vd., 2009). Irmağın aylık ortalama debisi nisan'da en yüksek $\left(241.14 \mathrm{~m}^{3} / \mathrm{s}\right)$ eylül'de en düşüktür $\left(37 \mathrm{~m}^{3} / \mathrm{s}\right)$ (Yıldırım vd., 2018). Göksu Irmağı su kalitesi Gibbs diyagramına göre "Su-Kayaç Etkileşimi" bölgesinde yer alırken; Piper diyagramına göre ise $\mathrm{Ca}-\mathrm{Mg}$ $\mathrm{HCO}_{3}$ sınıfı sulardan oluşmaktadır (Yıldırım vd., 2018; Demirel vd., 2011). Göksu Irmağının pH değerleri farklı araștırmacılar tarafından 7,5-8,6 (Kılıç, 2020), 7-8,9 (Demirel vd., 2011), 7,7-8,5 (Y1ldırım vd., 2018) ve 7,28,6 (Akbulut vd. 2009) aralığında belirlenmiştir. Irmağın elektriksel iletkenlik değeri $393 \mu \mathrm{S} / \mathrm{cm}$ ve çözünmüş oksijen içeriği 8 mg/L'dir (Demirel vd., 2011). Başka bir çalışmada ise özünmüş oksijen konsantrasyonu ortalama 8,3 mg/l (4,2-11,6 mg/l aralığında) olarak belirlenmiştir (Kılıç, 2020). Sıcaklık değerleri Demirel vd. (2011) tarafından 11-34 ${ }^{\circ} \mathrm{C}$; Y1ldırım vd. (2018) tarafından ise 14$24{ }^{\circ} \mathrm{C}$ aralığında bildirilmiştir. Kılıç (2020), su kalitesinin pH, ÇO, KOİ, $\mathrm{SO}_{4}, \mathrm{Na}^{+}, \mathrm{TÇK}, \mathrm{NO}_{3}$ parametreleri bakımından I. Sınıf; BOİ açısından I.-II. Sınıf; $\mathrm{NO}_{2}$ ve $\mathrm{NH}_{4}{ }^{+}$parametreleri bakımından I-IV. sınıf olduğunu bildirmiștir.

Göksu Irmağı havzası sınırlarında gerçekleştirilen örnekleme çalışmaları havzanın üç farklı bölgesi esas alınarak yapılmıştır. I. Bölge: Göksu Irmağı'nın Hadim Göksuyu olarak da bilinen kuzey havzasını oluşturmaktadır. II. Bölge: Göksu Irmağı'nın Ermenek Göksuyu (Gevne Çayı) olarak da bilinen güney havzasını oluşturmakta, III. Bölge: Suçatı (Mut ilçe merkezi) mevkisinden Silifke Regülatörü'ne kadar olan kısmı kapsamaktadır (Şekil 1).

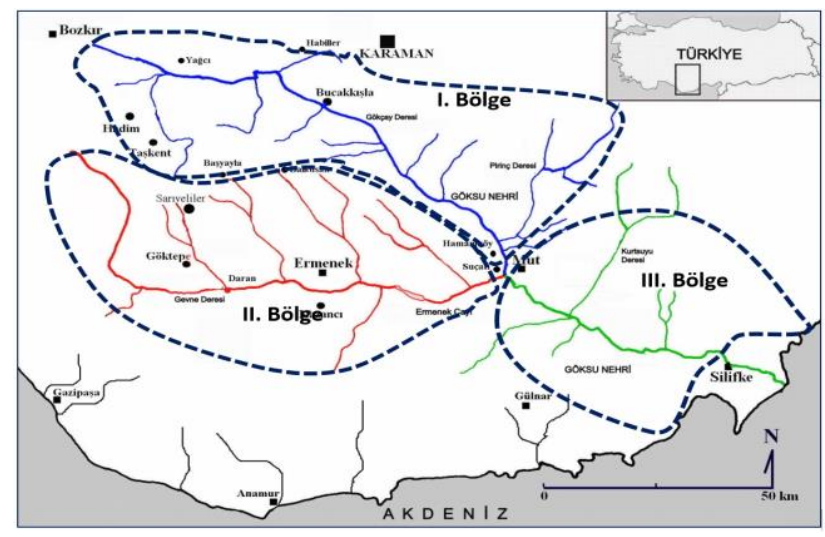

Şekil 1. Göksu Irmağı ve örnekleme bölgeleri (I. Bölge: Hadim Göksuyu olarak da bilinen kuzey havzası, II. Bölge: Ermenek Göksuyu veya Gevne Çayı, III. Bölge: Suçatı (Mut) mevkisi- Silifke Regülatörü arası, I. ve II. bölgeler ırmağın Yukarı Havzasını, III. Bölge ise aşağı havzasını oluşturmaktadır).

Figure 1. Göksu River and sampling regions (Region I: northern basin, also known as Hadim Göksuyu, Region II: Ermenek Göksuyu or Gevne Stream, Region III: between Süçatı (Mut) location- Silifke Regulator, regions I and II upstream of the river. Basin and Region III constitutes its lower basin). 


\section{Bölge (Hadim Göksuyu): Yukarı Göksu} Havzasının kuzeydeki kollarını kapsayan bölge, Göksu Irmağı'nın yaklaşık 1500 m yükseltide doğduğu Dedemli Köyü (Hadim) ile Suçatı (Mut) arasında kalan ve akarsuyun dağlık ve engebeli bölgelerden oluşur. Irmak üst bölgede Dedemli kaynaklarının yanı sıra Hadim yönünden gelen Balcılar Çayı ile de beslenir. Bölgede akarsu yatağının eğimi oldukça yüksek olduğundan çoğunlukla derin vadiler ve kanyonlar oluşur. Suyun rengi ve görünümü taşkın dönemleri dışında (Aralık-Mart) maviturkuaz renktedir (Şekil 2 ve 3).

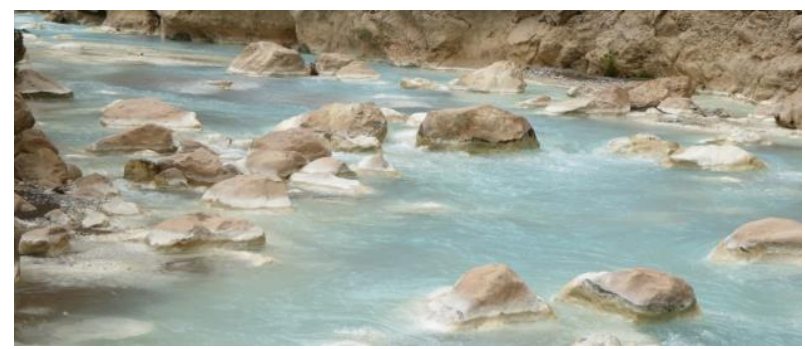

Şekil 2. Irmak yatağındaki su içerisinde kalan kayalar üzerinde yoğun kireç tabakası ile kaplanmış karakteristik bir bölgesi (Şahinbükü MevkisiBucakkışla).

Figure 2. A characteristic region (Şahinbükü Locality-Bucakkıșla) covered with dense lime layer on the rocks remaining in the water in the river.

Kaynak bölgesindeki dere ve çaylar üzerinde Avşar ve Bozkır barajları yapılmıştır. Bu barajlarda toplanan sular Bağbaşı Barajı'na aktarılarak, buradan "mavi tünel” aracılığı ile Beyşehir Sulama Kanalı'na bağlanmaktadır. 2021 y1lı içerisinde tamamlanması planlanan bu proje ile Göksu Irmağı'ndan yıllık yaklaşık 414 milyon $\mathrm{m}^{3}$ su, havza aktarımı yapılarak "Konya Kapalı Havzası'na" verilmesi amaçlanmaktadır (Anonim, 2021). Irmağın Bağbaşı Barajı ile Bucakkışla (Karaman) arasındaki kesiminde 3 adet Nehir Tipi HES bulunur. Söz konusu su yapıları ile ırmağın suları yaklaşık 3750-4000 m uzunluğundaki yapay bir kanala alınarak, yeterli yükselti fark1 (yaklaşı $100 \quad \mathrm{~m}$ ) yaratılıp elektrik enerjisi üretilmektedir.

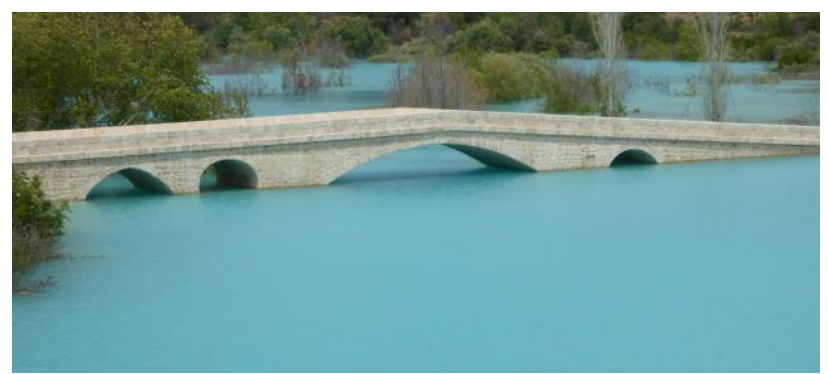

Şekil 3. Hadim Göksu'su üzerinde yapılan baraj sonucunda su altında kalmış olan Kravga Köprüsü (Bucakkışla).

Figure 3. Kravga Bridge (Bucakkışla), which was submerged as a result of the dam built on Hadim Göksu.

\section{Bölge (Gevne Çayı veya Ermenek Göksuyu):}

Yukarı Göksu Havzasının güneydeki kollarını içine alan bu bölgenin en önemli akarsuyu, Batı Toroslar'ın $2100 \mathrm{~m}$ yükseltilerindeki Geyik Dağları'ndan doğan ve yaklaşık $150 \mathrm{~km}$ uzunlundaki Gevne Çayı'dır. Bu çay, Mut ilçesi yakınlarındaki "Suçatı" bölgesinde kuzeyden gelen kol ile birleşerek Göksu Irmağı'nı oluşturur. Bu kol üzerinde 4 adet nehir tipi HES'in yanı sira Gezende ve Ermenek HES ve baraj gölleri de bulunur. Ancak çayın kaynak bölgesi ile Ermenek Baraj Gölü arasında kalan yukarı havzasında tipik "Alabalık Bölgesi” özelliği gösteren habitatlar bulunmasına karşın (Şekil 4), Çayarası (Alanya) bölgesinde kalan kısımlarının Alanya-Taşkent-Hadim karayolu inşası ve HES'lerin yapımı nedeniyle doğal yapısı büyük oranda tahrip olmuş, yer yer kurumuştur (Şekil 5).

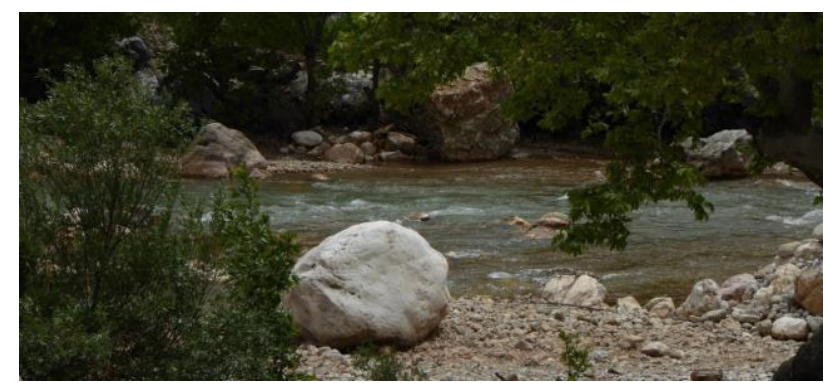

Şekil 4. Gevne Çayı, alabalık bölgesi (Çayarası-Alanya).

Figure 4. Gevne Stream, trout zone (Çayarası-Alanya).

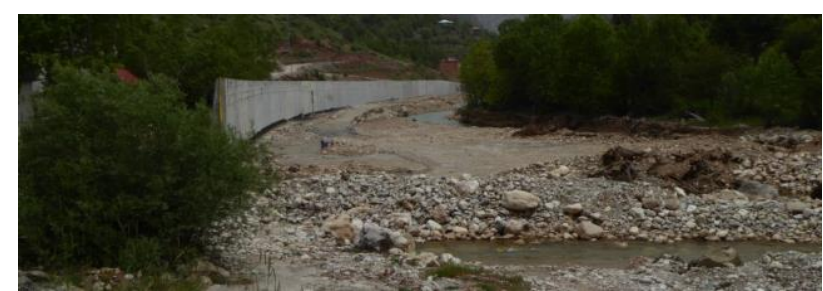

Şekil 5. Gevne Çayı'nda taşkın materyali ve rüsubat birikimi (ÇayarasıAlanya).

Figure 5. Flood material and sediment accumulation in Gevne Stream (Çayarasi-Alanya).

III. Bölge: Aşağı Göksu Havzası içerisinde, Silifke ilçe merkezinin yaklaşık $3 \mathrm{~km}$ kuzeyinde bulunan Silifke Sulama Regülatörü ile Suçatı (Mut) arasında kalan ve akarsuyun kuş uçuşu yaklaşık $60 \mathrm{~km}$ uzunluğundaki kesimidir (Şekil 6). Bu bölgeye akarsuyun acısu bölgesi dahil edilmemiştir. Bölgede akarsuyun eğimi görece azalarak menderesler oluşturmakta olup nehir yatağının genişliği genellikle 40-75 m'den yer yer 90-140 m'ye kadar ulaşmaktadır.

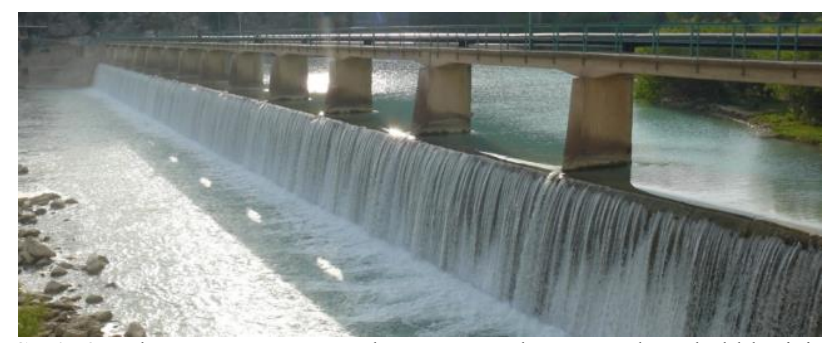

Sekil 6. Göksu Irmă̆ı'nın aşağı havza sınırı olan ve anadrom balıklar için engel oluşturan Silifke sulama regülatörü (Silifke)

Figure 6. Silifke irrigation regulator (Silifke), which is the downstream boundary of Göksu River and creates an obstacle for anadromous fish. 
Örnekleme: Çalışma 2014-2017 tarihleri arasında akarsuyun acısu bölgesi hariç tüm havzalarında gerçekleştirilmiştir. Örneklemeler, ırmağın akıntılı kesimlerinde elektroşoker ve serpme ağ yardımıla; aşağı havzadaki durgun bölgeler ve baraj göllerinde ise farklı göz açıklığındaki uzatma ağları ve ığrı yardımıla gerçekleştirilmiştir. Örnekleme çalışmalarının yanı sıra amatör balıkçılardan temin edilen balık örnekleri de kullanılmıştır.

Tanımlama ve Değerlendirme: Aynı alanda daha önce yapılan çalışmalar gözden geçirilerek örnekler karşıllaştırılmıştır. Bu karşılaştırmada, Isparta Uygulamalı Bilimler Üniversitesi Eğirdir Su Ürünleri Fakültesi İçsu Balıkları Koleksiyonu (IFC-ESUF) ve Recep Tayyip Erdoğan Üniversitesi Su Ürünleri Fakültesi Zooloji Müzesi (FFR) örnekleri de incelenmiştir. Familya isimleri
Schönhuth vd. (2018) ve Fricke vd. (2021)'ne göre düzenlenmiş, geçerli türler ise Turan \& Bayçelebi (2019), Küçük vd. (2014, 2017b), Yoğurtçuoğlu vd. (2021) ve Fricke vd. (2021)'den alınmıştır. Ayrıca taksonların Kırmızı Listedeki (IUCN, 2021-1) koruma durumları dikkate alınarak, popülasyonların mevcut durumları "artan", "sabit" ve "azalan" şeklinde değerlendirilmiştir.

\section{BULGULAR}

Göksu Irmağı'nın ana kolu ve Gevne Çayı'nda 2014-2017 tarihleri arasında yapılan örneklemelerde tespit edilen balık taksonları, dağılım alanları ve popülasyonların görece (gözlemsel) yoğunluk durumları $\operatorname{artan}(+)$, sabit $(*)$ ve azalan (-) şekilde Tablo 1'de verilmiştir.

Tablo 1. Göksu Irmağı'nın (acısu bölgesi hariç) güncel balık faunası, IUCN (2021-1) kırmızı liste kategorileri ve popülasyonların güncel durumları. Table 1. Current fish fauna of the Göksu River (excluding the brackish region),IUCN (2021-1) red list categories and current population status.

\begin{tabular}{|c|c|c|c|c|c|c|c|}
\hline Takson & 2007 & 2017 & 2021 & Dağılım Bölgesi & Kökeni & IUCN (2021-1) & Güncel Durum \\
\hline ANGUILLIDAE & & & & & & & \\
\hline $\begin{array}{l}\text { Anguilla anguilla } \\
\text { SALMONIDAE }\end{array}$ & + & + & + & 1,2 & Deniz/Katadrom & CR & $(-)$ \\
\hline $\begin{array}{l}\text { Salmo opimus } \\
\text { CYPRINIDAE }\end{array}$ & + & + & + & 3 & Tatlisu/Endemik & NE & $(-)$ \\
\hline Cyprinus carpio & + & + & + & 1,3 & Tatlisu & VU & $(-)$ \\
\hline Capoeta caelestis & + & + & + & $1,2,3$ & Tatlisu/Endemik & $\mathrm{LC}$ & $(-)$ \\
\hline Carassius gibelio & - & + & + & 1,3 & Tatlısu/Yabancı & $\mathrm{LC}$ & $(+)$ \\
\hline $\begin{array}{l}\text { Luciobarbus pectoralis } \\
\text { GOBIONIDAE }\end{array}$ & + & + & + & 1,2 & Tatlısu/Endemik & $\mathrm{LC}$ & $(*)$ \\
\hline $\begin{array}{l}\text { Gobio microlepidotus. } \\
\text { LEUCISCIDAE }\end{array}$ & + & + & + & 1,2 & Tatlisu/Endemik & $\mathrm{CR}$ & $(*)$ \\
\hline $\begin{array}{l}\text { Chondrostoma toros } \\
\text { NEMACHEILIDAE }\end{array}$ & + & + & + & 1,3 & Tatlısu/Endemik & $\mathrm{NE}$ & $(*)$ \\
\hline $\begin{array}{l}\text { Seminemacheilus tubae } \\
\text { ATHERINIDAE }\end{array}$ & + & + & + & 1,2 & Tatlısu/Endemik & $\mathrm{NE}$ & $(*)$ \\
\hline $\begin{array}{l}\text { Atherina boyeri } \\
\text { POECILIDAE }\end{array}$ & & + & + & 2 & Deniz & $\mathrm{LC}$ & $(+)$ \\
\hline Gambusia holbrooki & + & + & + & 1,2 & Tatlısu/yabancı & $\mathrm{LC}$ & $(*)$ \\
\hline
\end{tabular}

I. Bölge'de yapılan örneklemeler ve gözlemlerimizde söz konusu su yapılarının bulunduğu akarsu kesimlerinde yer yer kurumalar oluştuğu, dolayısıyla akarsuyun doğal akış rejiminin etkilendiği belirlenmiştir. Bölgenin baskın türü Capoeta caelestis (Toros sirazı)'tir. Ancak bölgedeki HES'ler bu türün popülasyonunun parçalanmasına, dolayısıyla yoğunluklarının azalmasına neden olmaktadır (Şekil 7).

Bölgede yaygın olan diğer türlerden Anguilla anguilla (yılanbalığı) ve Luciobarbus pectoralis (Asi bıyıklıbalığı)'in denizden yaklaşık 90-100 km içerdeki Bucakkışla yakınlarına kadar ulaştıkları, ırmağın endemiklerinden Chondrostoma toros (Toros kababurun balığı)'un ise Suçatı bölgesine kadar yayılış gösterdiği belirlenmiștir. Akarsuyun Alanözü ve Habiller (Güneysınır-Konya) yakınlarındaki en üst kollarında yoğun olmayan Gobio microlepidotus ve Seminemacheilus tubae popülasyonlarına rastlanır. Ayrıca ergin yılanbalı̆̆ bireylerinin denizden yaklaşı $150 \mathrm{~km}$ mesafede olan
Bucakkışla mevkilerine kadar ulaştıkları ve bu bölgede yerel avcılar tarafından avlandıkları tespit edilmiştir.

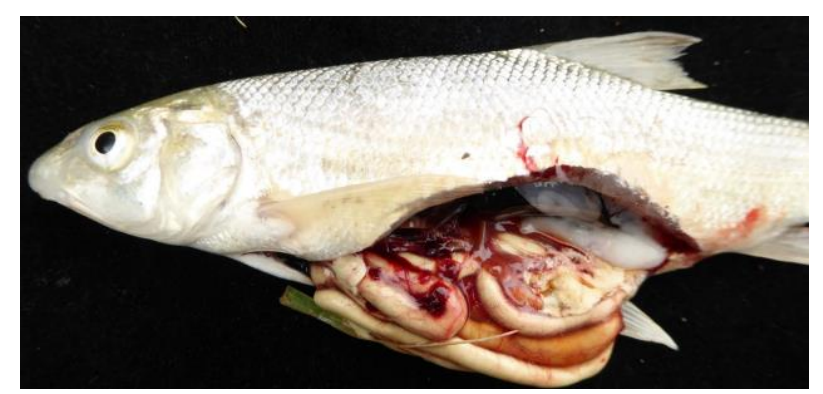

Şekil 7. Irmak yatağındaki kireç kaymağı tutmuş kayaları kazıyarak beslenen C. caelestis 'in kireç tortusu ile dolu sindirim kanalı (ŞahinbüküBucakkışla).

Figure 7. Digestive tract filled with lime deposits of $C$. caelestis fed by scraping the lime-cream-covered rocks in the river (ŞahinbüküBucakkışla).

II. Bölge'de, ağırlıklı olarak Gevne Çayı'nda 2004-2009 yılları arasında yaptığımız örneklemelerde $C$. caelestis'in baskın balık türü olduğunu, ancak; 2014-2017 
yılları arasındaki örnekleme ve gözlemlerde, yukarıda sözü geçen su yapıları nedeniyle, akarsu rejiminin değişmesi ve bazı bölgelerinin yer yer kurumasına bağlı habitat kayıpları sonucunda popülasyonların büyük oranda parçalandığı ve türün yoğunluğunun yaklaşık on yıl öncesine göre büyük oranda azaldığı belirlenmiştir.

Ermenek Baraj Gölü'ne Elmayurdu yakınlarında dökülen Kapız Dere'den 10.10.2004 tarihinde 1 adet ve Çayarası (Alanya) bölgesinden 18.10.2009 tarihinde 2 adet Salmo opimus (Kirmızıbenekli alabalık) bireyi yakalanmıştır. Ancak 2014-2017 tarihlerinde aynı habitatlarda yaptığımız örneklemelerde ise Çayarası bölgesinde söz konusu balıklara rastlanılmazken; Ermenek Baraj Gölü’ne dökülen Kapız Dere'de (Güneyyurt) 2015 ve 2016 yılında yoğun olmayan bir popülasyon tespit edilmiştir (Şekil 8,9). Fakat bu popülasyonun da çok düşük yoğunlukta olduğu, olası gökkuşağı alabalığı predasyonu ve aşırı avcılık nedeniyle yok olma tehlikesi ile karşı karşıya bulunduğu izlenmiştir.

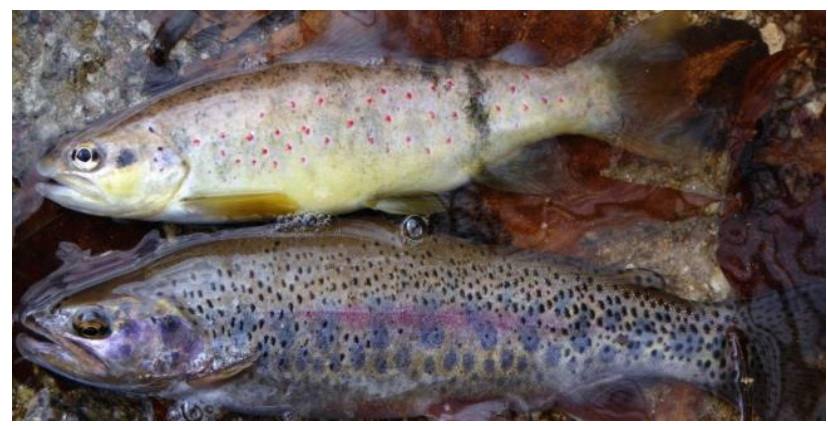

Şekil 8. Kapız Dere'de (Güneyyurt-Ermenek) aynı habitatı paylaşan $S$. opimus (üst) ve $O$. mykiss (alt).

Figure 8. S. opimus (top) and O. mykiss (bottom) sharing the same habitat in Kapız Dere (Güneyyurt-Ermenek).

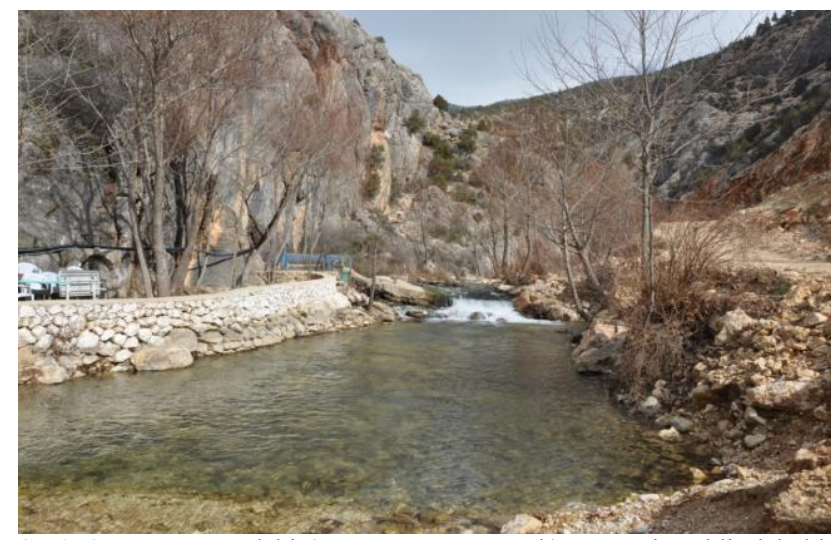

Şekil 9. Kapız Deredeki (Güneyyurt, Ermenek) kırmızıbenekli alabalık habitatı üzerinde bulunan bir alabalık çiftliği.

Figure 9. A trout farm located on the Ceyhan trout habitat in Kapız Creek (Güneyyurt, Ermenek).

2012 y1lında işletmeye açılan Ermenek Baraj Gölü'nde ise A. boyeri, C. carpio, C. gibelio ve $O$. mykiss türlerinin varlığ 1 belirlenmiştir. Akarsuyun diğer bir kolu olan Balkusan Deresi'ndeki örneklemelerde (yaklaşık 150 $\mathrm{m}^{2}$ ) 75-80 adet Gobio microlepidotus ve 2-3 adet Capoeta caelestis bireyine rastlanmıştır.

III. Bölge'de akarsu yatağ 1 çevresinde yoğun meyvecilik tarımı yapılmakta, bunun yanında akarsu yatağında yer yer kum-çakıl ocakları bulunmaktadır. Suyun rengi ve görünümü aralık-mart aylarında yoğun alüvyon taşınması nedeniyle bulanık, diğer dönemler ise mavi-turkuaz görünüşlüdür. Nehir ağzından yaklaşık 25 $\mathrm{km}$ yukarıya kurulmuş olan 3,5-4 m yüksekliğindeki Göksu Sulama Regülatörü'nün deniz-tatlısu arasında göç eden (diyadrom) balıkların akarsu içindeki hareket ve dağı̆lımlarını önemli ölçüde etkilediği gözlemlenmiştir.

Regülatörden denize kadar olan acısu bölgesinde denizel kökenli Sparidae, Moronidae, Carangidae, Soleidae, Sciaenidae, Sillaginidae ve Engraulidae familyası üyesi türlerin yanı sıra; Anguillidae, Mugilidae ve Clupeidae üyesi göç eden (diyadrom) türler ile tatlısu kökenli Aphanius fasciatus, Acanthobrama orontis, Capoeta caelestis, Chondrostoma toros, Luciobarbus pectoralis, Clarias gariepinus, Pomatoschistus anatoliae, Gambusia holbrooki ve Oreochromis niloticus olmak üzere toplam 32 tür kaydı verilmiştir (İnnal vd., 2020).

Ancak regülatörün hemen altında, deniz tarafinda, yaptığımız örneklemelerde tatlısu kökenli türlerin (A. anguilla, $C$. caelestis $C$. toros ve $L$. pectoralis) baskın oranda bulunduğu belirlenmiştir. Irmağın acısu bölgesinde çok yoğun olarak bulunan denizel kökenli Mugilidae ve Clupeidae üyesi bazı türlerin yaklaşık $3,5-4 \mathrm{~m}$ yüksekliğindeki regülatöre kadar ulaştıkları, ancak daha üst bölgelere geçemedikleri izlenmiştir. Göksu Deltası'ndaki drenaj kanallarında Kaya vd. (2020) tarafindan tanımlanan Oxynoemacheilus cilicicus'a ise bu çalışmada ırmak gövdesinde rastlanamamıştır.

\section{SONUÇ}

Akdeniz Bölgesi'nin en önemli akarsularından olan bir olan Göksu Irmağı'nda 2014-2017 yılları arasında farklı tarihlerde yaptığımız örnekleme ve gözlemler ile bölgede yapılan diğer ihtiyofauna kayıtlarının değerlendirilmesi sonucunda; ırmağın acısu bölgesi hariç, aşağı ve üst havzasında 11 balık türü tespit edilmiştir.

Söz konusu türlerden Chondrostoma toros (Toros kababurun balığı) Göksu Irmağ türdür. Diğer türlerden Salmo opimus ve Capoeta caelestis Akdeniz Bölgesi'ndeki akarsularda (Kaya vd., 2019), Gobio microlepidotus ise Göksu Irmağı'nın üst bölgesinin yanı sıra Beyşehir Gölü havzasında da yayılış gösterir (Turan \& Bayçelebi, 2019). Gobio microlepidotus ile aynı habitatı paylaşan ve ilk olarak Çiçek (2020) tarafindan Alanözü Baraj Gölü'nden tanımlanan Seminemacheilus dursunavsari, ICZN kriterlerini karşılamaması sebebiyle nomen nudum olarak kabul edilmiş ve Yoğurtçuoğlu vd. 
(2020) tarafindan Seminemacheilus tubae ismiyle yeniden tanımlanmış ve taksonomik durumu sabitlenmiştir (Yoğurtçuoğlu vd., 2021).

2014-2017 yılları arasındaki örnekleme ve gözlemlerimizde Gevne Çayı'ndaki Salmo opimus popülasyonunun yok olduğu, Kapız Dere popülasyonunun ise regülatör yapısı, olası gökkuşağı alabalığı predasyonu ve amatör balıkçı baskısı nedeniyle büyük tehlike altında bulunduğu belirlenmiştir. Örneklemelerimizde yerel adı "ak memet" olan ve Asi, Ceyhan, Seyhan rrmaklarında da yaşayan Luciobarbus pectoralis, Göksu Irmağı'nın aşağ 1 havzasında yayılış göstermekle birlikte, akarsu ağzı bölgesinde dahi zaman zaman yoğun popülasyonlar oluşturmaktadır. Doğu Akdeniz bölgesi akarsularında yaşayan diğer bir tür Acanthobrama orontis (Küçük vd., 2014; İnnal vd., 2020)'in Silifke sulama regülatörünün altında kalan bölgeyi tercih ettiği gözlenmiştir.

Kaynak bölgesindeki çaylar üzerine DSI tarafindan yapılan "Mavi Tünel Projesi" ile bölgedeki bazı balık türlerinin Konya Kapalı Havzası'na geçişi sağlanacağı, bu nedenle popülasyon genetiği yönüyle ilgili türlerin izlenmesi gerektiği düşünülmektedir. Dedemli (Hadim) ile Bucakkışla (Karaman) arasında kalan bölgede kurulan çok sayıda nehir tipi HES projeleri üzerindeki balık geçitlerinin işlevsiz oluşu ve akarsu yatağının zaman zaman kuruması, akarsu içinde göç eden balıkların yoğunluklarının azalmasına neden olduğu 2004, 20142017 yılı örneklemelerimizde belirlenmiştir. Akarsuyun aşağı havzasında (Suçatı bölgesi ile Silifke sulama regülatörü arası) balıkların göç ve yayılışlarını engelleyen en önemli yapı yaklaşık $4 \mathrm{~m}$ yüksekliğindeki Silifke sulama regülatörüdür. $\mathrm{Bu}$ regülatör göç eden türler açısından, akarsuyun aşağı ve yukarı havzalarını birbirinden bıçak gibi ayırmaktadır. Özellikle yılanbalığı elverleri, Asi bıyıklı balığı ve kefallerin bu engeli aşamadığı görülmektedir. Limnodrom ve diadrom balık göçlerine engel olan ve yüksekliği çok fazla olmayan bu bariyerin balık asansörü, balık savağı, balık burgusu, balık merdiveni ve sslak boru yöntemleriyle çok kolay ve düşük maliyetli uygulamalar ile aşılması mümkün görünmektedir. Ayrıca akarsu yatağının kum-çakıl ocağı şeklinde kullanımı, habitatları olumsuz etkileyen diğer baskılar olarak değerlendirilmiş̧tir.

Göksu Irmağı jeolojik yapısının ve topoğrafyasının bir sonucu olarak bazı kesimlerde insan yerleşimi ve ulaşım açısından zorlu koşullar göstermekle birlikte, hemen hemen tüm kesimlerinde insan müdahalesine maruz kalmış ve doğal özelliğini önemli ölçüde yitirmiş bir akarsudur. Akarsuyun balık faunası üzerinde barajlar, nehir tipi HES'ler, regülatörler, yoğun su çekimleri sonucu oluşan kuruma ve kuraklık olayları başlıca tehdit unsurları olmakla birlikte; küçük akarsulardaki kaçak avcılık faaliyetleri ve akarsu yatağı tahribatları diğer önemli olumsuzluklar olarak tespit edilmiştir.

Önümüzdeki süreçte, orta-uzun vadede, özellikle yağış-akış rejimlerine bağlı hidrolojik düzensizliklerin balık faunası üzerinde en yıkıcı etkiyi oluşturacağ düşünülmektedir. $\mathrm{Bu}$ durumun önlenmesi için, ırmağın kılcal beslenme damarlarını oluşturan küçük-orta büyüklükteki kollarında mutlaka yeterli su akışının sağlanması gerekmektedir. Mevzuatta (RG, 15 Haziran 2019, 30802 "Elektrik Piyasasinda Üretim Faaliyetinde Bulunmak Üzere Su Kullanım Hakki Anlaşması Imzalanmasına İlişkin Usul ve Esaslar Hakkında Yönetmelik") yer verilen “...doğal hayatın devamı için mansaba birakilacak su miktart projeye esas alınan son on yıllık ortalama akımın en az \%10'u kadar olmak zorundadır." şeklindeki \%10'luk cansuyu veya çevresel akış oranı uygulansa bile yetersiz kaldığı gözlemlenmiştir. Zira özellikle yukarı havzadaki yan kolların çok değişken debili ve kırılgan bir ekosistem yapısında olduğu görülmektedir. Ayrıca akarsuyun sığ yatak bölgelerinde yapılan düzleştirilme, genişletme ve küreme gibi makinalı kazıların balıkların saklanma ve beslenme alanlarını tamamen ortadan kaldırdığı gözlemlenmiş olup, bu durumlara son verilmesi gerekmektedir.

\section{KAYNAKLAR}

Anonim. (2021). DSİ, IV. Bölge Müdürlüğü, Konya.

Akbulut, N., Bayarı, S., Akbulut, A. \& Şahin, Y. (2009). Rivers of Turkey. In Rivers of Europa, Tockner K, Robinson CT, Uehlinger $U$ (eds). Elsevier, Academic Press: New York; 643-772.

Balık, S. (1980). Güney Anadolu Bölgesi içsularında yaşayan tatlisu balıklarının sistematik ve zoocoğrafik yönden araştırılması. Ege Üniversitesi Fen Fakültesi Biyolojik Oseanografi Bölümü (Doçentlik Tezi), İzmir, Türkiye, $139 \mathrm{~s}$.

Bogustkaya, N. (1997). Chondrostoma beysehirense, a new cyprinid fish from Beyşehir Lake, Central Turkey. Ichthyological Exploration of Freshwaters, 8(2), 151-158.

Çiçek, E. (2020). Seminemacheilus dursunavsari, a new nemachelid species (Teleostei: Nemacheilidae) from Turkey. Iranian Journal of Ichthyology, 7(1), 68-77. DOI: 10.22034/iji.v7i1.494

Demirel, Z., Özer, Z. \& Özer, O. (2011). Investigation and modeling of water quality of Göksu River (Cleadnos) in an international protected area by using GIS. Journal of Geographical Sciences, 21(3), 429-440. DOI: 10.1007/s11442-011-0855-4

Fricke, R., Eschmeyer, W.N. \& Fong, J.D. (2021). Eschmeyer's catalog of fishes: genera/species by family/subfamily.

http://researcharchive.calacademy.org/research/ic hthyology/catalog/Species By Family.asp, 28 Eylül 2021. 
İnnal, D., Tocan, B., Gülle, İ., Çağlan, D.C., Dügel, M. \& Avşar, D. (2020). Diversity and distribution of the ichthyofauna in the Göksu River estuary, Turkey. Acta Zoologica Bulgarica, 72(4), 667676.

Kaya, C., Küçük, F., Turan, D.(2019). New Data on the Distribution and Conservation Status of the Two Endemic Scrapers in the Turkish Mediterranean Sea Drainages (Teleostei: Cyprinidae). International Journal of Zoology and Animal Biology, 2(9), 000185. DOI: 10.23880/izab16000185

Kaya, C., Turan, D., Bayçelebi, E., Kalaycı, G. \& Freyhof, J. (2020). Oxynoemacheilus cilicicus, a new nemacheilid loach from the Göksu River in southern Anatolia (Teleostei: Nemacheilidae). Zootaxa, 4808(2), 284-300. DOI: 10.11646/zootaxa.4808.2.3

Kılıç, E. (2020). Evaluation of water quality by water quality index method using long time monitoring data in Göksu River. Marine and Life Sciences, 2(1), 5-12.

Küçük, F., Gümüş, E., Gülle, İ. \& Güçlü, S.S. (2007). The Fish fauna of the Göksu River (Türkiye): Taxonomic and zoogeographic features. Turkish Journal of Fisheries and Aquatic Sciences, 7, 5363.

Küçük, F., Bektaş, Y., Güçlü, S.S. \& Kaya, C. (2014). The systematic position of Acanthalburnus microlepis (De Filippi, 1863) and contributions to the genus Acanthobrama (Cyprinidae: Leuciscinae) in Turkey. Iranian Journal of Ichthyology, 1(2), 96-105.

Küçük, F., Gülle, İ. \& Güçlü, S.S. (2017a). Karaman ili'nin karasal ve iç su ekosistemleri biyolojik çeşitlilik envanter ve izleme işi sonuç raporu. EMS Çevre Araştırmaları Sosyal Hizmetler ve Eğitim Danışmalık Tic. Ltd. Şti. Ankara.

Küçük, F., Turan, D., Güçlü, S. S., Mutlu, A. G. \& Çiftci, Y. (2017b). Two new species of Chondrostoma Agassiz, 1832 (Teleostei: Cyprinidae) from the Ceyhan, Seyhan and Göksu rivers in the East Mediterranean region of Turkey. Turkish Journal of Fisheries and Aquatic Sciences, 17, 795-803. DOI: 10.4194/1303-2712v17_4_15

Ladiges, V.W. (1966). Sübwasserfische der Türkei 4. Teil: Die Gattung Chondrostoma (Cyprinidae) in der Türkei. Cyprinidae. Mitt. Hamb. Zool. Mus. Inst. Band, 63, 101-109.

Munsuz, N. \& Ünver, İ. (1983). Turkey freshwater. Ankara Üniversitesi Ziraat Fakültesi Yayınları (882-247), Ankara, 392 s.

Schönhuth, S., Vukić, J., Šanda, R., Yang, L. \& Mayden, R.L. (2018). Phylogenetic relationships and classification of the Holarctic family Leuciscidae (Cypriniformes: Cyprinoidei). Molecular Phylogenetics and Evolution, 127, 781-799. DOI: 10.1016/j.ympev.2018.06.026

Tekin, S. \& Can, T. (2019). Göksu Nehri Havza’sının jeomorfometrik analizler ile değerlendirilmesi.
Uluslararası Katılımlı 72. Türkiye Jeoloji Kurultayı 28 Ocak-01 Şubat 2019, Ankara.

Turan, D. \& Bayçelebi, E. (2019). Range Extension of Gobio microlepidotus Battalgil, 1942 in the Southern Anatolia (Pisces: Cyprinidae). Journal of Anatolian Environmental and Animal Sciences, 4(2), 156-160. DOI: 10.35229/jaes.556220

Yıldırım, Ü., Güler, C., Kurt, M.A. \& Geçgel, C. (2018). Göksu Nehri akış yolu boyunca ana element değişimlerinin İncelenmesi. HIDRO'2018: Ulusal Hidrojeoloji ve $\mathrm{Su}$ Kaynaklarl Seтроzуити, Ankara, Turkey. Proceedings Book, 206-213.

Yoğurtçuoğlu, B., Kaya, C., Geiger, F. M. \& Freyhof, F. (2020). Revision of the genus Seminemacheilus, with the description of three new species (Teleostei: Nemacheilidae). Zootaxa 4802(3), 477-501. DOI: 10.11646/zootaxa.4802.3.5

Yoğurtçuoğlu, B., Kaya. C. \& Freyhof, J. (2021). Oxynoemacheilus nasreddini, a new nemacheilid loach from Central Anatolia (Teleostei: Nemacheilidae). Zootaxa 4974(1), 135-150. DOI: 10.11646/zootaxa.4974.1.5 